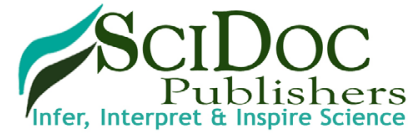

\section{Effectiveness of a Program for Promoting Physical Activity to Prevent Obesity among Grade 4-6 Students in Northern Thailand}

\section{International Journal of Chronic Diseases \& Therapy (IJCDT) ISSN 2572-7613}

Songthap $\mathrm{A}^{1 *}$, Wongsawat $\mathrm{P}^{1}$, Phong-ek Suksai ${ }^{2}$

${ }^{1}$ Department of Community Health, Faculty of Public Health, Naresuan University, Thailand.

${ }^{2}$ Department of Physical Education and Exercises Science, Faculty of Education, Naresuan University, Thailand.

\title{
Abstract
}

Inadequate physical activity among school children can lead to overweight and obesity. This two-group pretest-posttest quasi-experimental study proposed to assess the effectiveness of a program for promoting physical activity to prevent obesity among grade 4-6 students in Pho Prathap Chang District, Phichit Province, northern Thailand. A total of 120 samples were students studying in grade 4-6 selected using systematic random sampling. The subjects were classified into 2 groups, the intervention group and the control group. Each group consisted of 60 subjects. Data were obtained using a questionnaire. The questionnaire was tested using KR20 for knowledge and Cronbach's alpha coefficient for the attitude and their reliabilities were 0.87 and 0.83 , respectively. Data were analyzed using frequency, percentage, mean, standard deviation, chi-square test, t-test, and McNemar test. The results indicated that after intervention, the intervention group had significantly higher mean scores of knowledge and attitude before intervention $(\mathrm{p}<0.001)$. The body mass index (BMI) of the intervention group decrease significantly $(p=0.001)$ and proportion of adequate physical activity increased significantly $(p<0.001)$. However, there was no significantly difference of knowledge, attitude, BMI, and physically activity in the control group. The program for promoting physical activity to prevent obesity among 4-6 students is effective in the intervention group. Therefore, the related institution should employ this program in the targeted students to promote physical activity.

Keywords: Effectiveness; Program, Knowledge; Attitude; Body mass index; Physical activity; Grade 4-6 students; Obesity.

\section{Introduction}

Lack of body movement or physical activity results in the body being unable to burn all the energy that has been received. It can cause the accumulation of fat in different parts of the body and eventually leading to obesity [1]. The obesity measurement can be calculated by the body mass index (BMI) and then comparing it to the BMI table according to age. If it is over 95 percentile of the criteria, it is considered to be overweight [2]. Overweight and obese children are likely to stay obese into adulthood and more likely to develop non-communicable diseases such as diabetes and cardiovascular diseases at a younger age. Further, obese children may lose of self-esteem and some of them are more aggressive than normal weight children. This might leads to depression [3].

The prevalence of overweight and obesity in children and adolescents has increased worldwide. It was estimated that 170 million children under 18 years of age were overweight or obese in 2008 and approximately $30 \%$ of all children will be affected by these conditions in 2030 [4]. In Thailand, the Department of Health, Ministry of Public Health reported the prevalence of overweight and obesity among school children in 2018 was high as $15 \%$ and physically active children was only $25 \%$ [5].

In 2017, Pichit Province had overweight and obese students was $15.7 \%$ which is the highest proportion in northern Thailand whereas Pho Prathap Chang District had overweight and obese children was $16.2 \%$ and was the highest rate in Pichit Province [6]. Therefore, the problem of obese children in Pho Prathap Chang District should be solved to reduce the risk of chronic diseases and its consequences in the future.

According to the previous studies, the intervention program applied the TCM (Tran-Theoretical Model) for parents who had

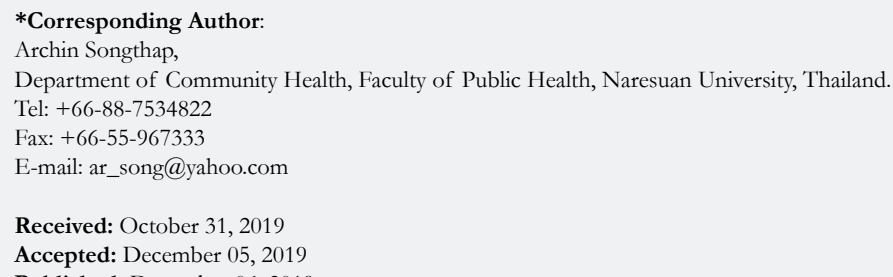

Copyright: Songthap $\mathbf{A}^{\circ}$ 2019. This is an open-access article distributed under the terms of the Creative Commons Attribution License, which permits unrestricted use, distribution and reproduction in any medium, provided the original author and source are credited. 
obese children by counselling them about diet and exercise control over the phone for a period of 6 weeks and then assessing the results at the following 3 months. The study reported that after intervention the body mass index (BMI) in the intervention group reduced significantly compared to the control group $(p<0.05)[7]$. In addition, other intervention studies provided knowledge and attitude about diet and exercise programs for parents of obese children. Then, the studies followed up to assess the BMI of children. These studies found the BMI decreased significantly [8$10]$.

From such problems, the researchers, therefore, conducted the study on the effectiveness of a program for promoting physical activity to prevent obesity among grade 4-6 students in northern Thailand applied by the TCM. The study aimed to assess the effectiveness of the program before and after intervention. The results of this study can be utilized as a guideline for targeted students to change their physical activity behaviour to reduce the $\mathrm{BMI}$ and prevent obesity in adolescent and adult. The results also can prevent chronic diseases and psychological and social impacts in the future.

\section{Objectives}

\section{General Objective}

To study the effectiveness of a program for promoting physical activity to prevent obesity among grade 4-6 students.

\section{Specific Objectives}

1. To compare knowledge, attitude, body mass index, physical activity in intervention group and control group before and after intervention.

2. To compare knowledge, attitude, body mass index, physical activity between intervention group and control group after intervention.

\section{Materials and Methods}

\section{Study Design and Subjects}

This was a two-group pretest-posttest quasi-experimental study. We conducted this study between November 2017 and May 2018. The study populations were grade 4-6 students in Pho Prathap Chang District, Pichit Province who were studying in grade 4-6 at 14 public schools. Then, two schools were selected, one for the intervention group and the other for the control group, by simple random sampling technique.

A total of 120 subjects were recruited, including 60 subjects in the intervention group and 60 subjects in the control group. The sample size was calculated based on the previous survey [11] which found that physically active among grade 4-6 students was $20.5 \%$. The present study expected to increase this proportion up to $45.0 \%$ after intervention with $5 \%$ error, $95 \%$ confident interval, and $80 \%$ of the power. Then, a total of 120 subjects were included in this study. The study subjects were chosen using systematic random sampling from grade 4-6 students at the study schools. Inclusion criteria for the study subjects were:
1) aged 9-12 years, 2) being able to read and write Thai, and 3) being willing to participate in the study. The exclusion criteria were: 1) wanting to withdraw from the study, 2) not being able to participate throughout the program, and 3) being with some underlying diseases that may be affected by exercise.

\section{The Study Tools}

There were 2 study tools in this study including a questionnaire and a program for promoting physical activity.

\section{The questionnaire consisted of:}

1) General characteristics include gender, age, grade, number of siblings, birth order, daily pocket money, and chronic disease (allergy and asthma) in the total of 7 items; multiple choices and short answer.

2) Knowledge of physical activity consisted of 10 items with multiple choices; giving one point for each correct answer and 0 point for each incorrect answer.

3) Attitude about physical activity included 10 items using 3- level of Likert's scale, where 1 meant disagree, 2 meant neutral, and 3 meant agree.

4) Body mass index obtained from physical measurement, including weight in kilograms compared with the height in meters squared.

5) Physical activity in this study followed the definition of the previous study [12]; physical movement included recreation and sports activities, such as jumping rope, playing football, running, weight lifting and daily activities, such as walking, climbing, walking ascending and descending stairs. Physical activity was recorded as frequency in number of time per week in munities spent in physical activity. The physical activity was categorized as adequate $(\geq 7$ hours per week) and inadequate ( $<7$ hours per week).

2. A program to promote physical activity for grade 4-6 school students applied by the theory of Trans theoretical Model or Stage of Change Model [13] consisted of 5 steps; Step 1, Precontemplation (Week 1): This step aimed to encourage students to be interested in physical activity. The researchers organized activities by promoting knowledge to stimulate students to gain and be aware about physical activity and proper eating. Step 2: Contemplation (Week 2): This step provided activities for students to analyze the advantages and disadvantages of physical activity including analyzing problems and obstacles when they did physical activity at school, home, and community. Step 3: Ready to practice (Preparation) (Week 3-5): This was a step of organizing physical activity programs in each day for students to perform. The researcher team provided equipment and environment for students to do physical activity. Then, the students were explained about the process of physical activity promotion program and demonstrated how to do exercise from stretching the muscles, exertion and relaxation. Students were allowed to choose their favorite sports or recreation to perform together. This step also provided sports and recreation competition for students. Step 4: Action (week 6-14): This step was to implement the physical activity promotion program, including basic movements, physical 
administration, exercise, sports and recreation activities such as stretching, running, jogging, sprinting, jumping rope, soccer, volleyball, ball throwing, rice ball, cinnabar, aerobics, dancing, music, etc. Step 5: Maintenance (Week 15-24): This step was a follow-up period to observe the sustainably behavioral change in physical activities.

\section{Questionnaire Assessment}

The content validity and reliability of the questionnaire were assessed by the experts and the questionnaire was tested among 30 grade 4-6 students not include in the study. The Cronbach's alpha coefficients were 0.87 for knowledge and 0.83 for attitude.

\section{Data Collection}

After the students were signed a consent, the researchers explained them the objectives of the program at the selected school and made the appointment with them to carry out the first data collection. The first data collection was conducted in the rooms at the selected schools by using the self- administered questionnaire. Once the questionnaires have been completed, the students were asked to measure their weight and height. The researchers processed and filled in the weighing and height into the questionnaire of each student. The following week, the researchers implemented the program to promote physical activity to the intervention group until completed and the second data collection was performed in the following week after the program ended (week 25).

\section{Statistical Analysis}

The data analyses were explored by SPSS version 20 for Windows. Categorical data of the subjects were described using frequency and percentage. Mean and standard deviation were used to present continuous data. Paired sample t-test was computed to compare the different mean score of knowledge, attitude, and BMI within the experimental group and the control group before and after intervention. Independent sample t-test was used to compare the different mean score of knowledge, attitude, and BMI between groups before and after intervention. The chi-square test was performed to compare the differences of general characteristics and socio-demography of the subjects between groups before intervention and levels of physical activity between groups after intervention. McNemar test was calculated to compare levels of physical activity within groups before and after intervention. A p-value $<0.05$ was considered significant.

\section{Ethical Considerations}

This study was approved by the Ethics Committee of Naresuan University (IRB: 0215/2017). In addition, the researchers explained study objectives, research methodology, benefit, and the expected risks that might arise to the subjects and allowed them to be able to leave this study at any time. Further, the information collected from this study was kept confidentially and the results presented for the overall.

\section{Results}

Characteristics and socio-demography compared between the intervention group and the control group were not different $(\mathrm{p}>0.05)$. The majority of the intervention group and the control group were male $(61.7 \%$ and $53.3 \%$ ) with age higher than 10 years old $(58.3 \%$ and $55.0 \%)$. Most of the intervention group and the control group studied in grade $5(38.3 \%$ and $36.7 \%)$. Sixty one point seven percent of the intervention group and $56.7 \%$ of the control group had total siblings 1-2 persons. The first and the second birth order of the intervention group was $95.0 \%$ and the control group was $91.6 \%$. Most of the intervention group and the control group had daily pocket money to school less than 1.7 US\$ $(68.3 \%$ and $60.0 \%$ ) and $86.7 \%$ of the intervention group and $93.3 \%$ of the control group had no chronic diseases (Table 1).

Table 2 showed significantly different mean score of knowledge, attitude and BMI within the intervention group before and after intervention $(\mathrm{p}<0.05)$. Mean score of knowledge increased from 6.83 to 8.22 , attitude rose from 2.30 to 2.83, and BMI decreased from 24.70 to $23.13 \mathrm{~kg} / \mathrm{m}^{2}$. Moreover, there were significantly differences and higher mean score of knowledge and attitude, and lower BMI in the intervention group than in control group after intervention (Data was not shown). However, there was no differences of these factors in the control group before and after intervention.

After intervention, there was significantly difference of physical activity in the intervention group $(\mathrm{p}<.05)$. The percentage of adequate physical activity raised from $25 \%$ to $81.6 \%$. There was also significantly difference $(\mathrm{p}<.05)$ when compared physical activity between the intervention group and the control group (Data was not shown). However, physical activity in the control group was not statistically significant after intervention.

\section{Discussion}

After implementing the program to promote physical activity for grade 4-6 students, the study found that mean score of knowledge and attitude were significantly higher whereas mean score of BMI was significantly lower. Further, percentage of physically active students were significantly greater in the intervention group than before intervention. However, there was no difference of these factors in the control group after intervention. Our study results were consistent with the studies related to physical activity in grade 4-6 school students. For example, Yammen and Duangsong studied the effects of health promotion programs to control the weight among grade 5 students with overweight in Mueang District, Phitsanulok Province [14]. The study of Uthachai and Buncharachakit implemented a program promoting food and exercise behavior to prevent overweight of grade 6 students in Khon Kaen Municipality. These two studies showed that the intervention group had knowledge about obesity, proper diet intake and exercise after intervention significantly higher than before intervention and the control group. Additionally, there was significantly lower body weight than before intervention and the control group $(p<0.001)$ [15]. Moreover, our results were in the line with the study of Kaewthet et al., which studied the effects of a program to promote food consumption behavior and physical activity in grade 4-5 students with overweight in schools under Bangkok Municipality. The results showed that the mean scores of dietary behavior and physical activity were higher than before intervention (p-value <0.001) [16]. According to the results from the previous studies, it can be explained that the intervention 
Table 1. Characteristics and socio-demography compared between the intervention group and the control group (Chi-square test).

\begin{tabular}{|c|c|c|c|}
\hline \multirow{2}{*}{$\begin{array}{l}\text { Characteristics and } \\
\text { socio-demography }\end{array}$} & $\begin{array}{l}\text { Intervention group } \\
(N=60)\end{array}$ & $\begin{array}{l}\text { Control group } \\
(N=60)\end{array}$ & \multirow[t]{2}{*}{ p-value } \\
\hline & $\mathbf{N}(\%)$ & $\mathbf{N}(\%)$ & \\
\hline \multicolumn{4}{|c|}{ Gender } \\
\hline Male & $37(61.7)$ & $32(53.3)$ & 0.641 \\
\hline Female & $23(38.3)$ & $28(46.7)$ & \\
\hline \multicolumn{4}{|c|}{ Age (year) } \\
\hline$<10$ & $25(41.7)$ & $2745.0)$ & 0.783 \\
\hline$\geq 10$ & $35(58.3)$ & $33(55.0)$ & \\
\hline \multicolumn{4}{|c|}{ Grade } \\
\hline Forth & $21(35.0)$ & 19(31.6) & 0.85 \\
\hline Fifth & $23(38.3)$ & $22(36.7)$ & \\
\hline Sixth & $16(26.7)$ & $18(31.6)$ & \\
\hline \multicolumn{4}{|c|}{ Total number of siblings } \\
\hline $1-2$ & $37(61.7)$ & $34(56.7)$ & 0.522 \\
\hline$\geq 3$ & $23(38.3)$ & $28(43.3)$ & \\
\hline \multicolumn{4}{|l|}{ Birth order } \\
\hline First or second & $57(95.0)$ & $55(91.7)$ & 0.834 \\
\hline Third or later & $3(5.0)$ & $5(8.3)$ & \\
\hline \multicolumn{4}{|c|}{ Pocket money per day (US\$) } \\
\hline$<1.7$ & $19(31.7)$ & $24(40.0)$ & 0.397 \\
\hline$\geq 1.7$ & $31(68.3)$ & $26(60.0)$ & \\
\hline \multicolumn{4}{|c|}{ Chronic disease (allergy and asthma) } \\
\hline No & $52(86.7)$ & $56(93.3)$ & 0.352 \\
\hline Yes & $8(13.3)$ & $4(6.7)$ & \\
\hline
\end{tabular}

Table 2. Comparison of mean score of knowledge, attitude, and BMI within the intervention group and the control group before and after intervention (Paired sample $\mathrm{t}-$ test) $(\mathrm{N}=60$ per group).

\begin{tabular}{|c|c|c|c|c|c|}
\hline Variable & Mean (SD) & Mean Difference & $\mathbf{t}$ & df & p-value \\
\hline \multicolumn{6}{|c|}{ Knowledge } \\
\hline \multicolumn{6}{|c|}{ Experimental group } \\
\hline Before & $6.83(1.32)$ & \multirow{2}{*}{-1.37} & \multirow{2}{*}{-10.948} & \multirow{2}{*}{59} & \multirow{2}{*}{$<0.001^{*}$} \\
\hline After & $8.20(1.11)$ & & & & \\
\hline \multicolumn{6}{|c|}{ Control group } \\
\hline Before & $6.94(1.45)$ & \multirow{2}{*}{0.08} & \multirow{2}{*}{1.362} & \multirow{2}{*}{59} & \multirow{2}{*}{0.348} \\
\hline After & $6.86(1.27)$ & & & & \\
\hline \multicolumn{6}{|c|}{ Attitude } \\
\hline \multicolumn{6}{|c|}{ Experimental group } \\
\hline Before & $2.30(0.89)$ & \multirow{2}{*}{-0.53} & \multirow{2}{*}{-6.626} & \multirow{2}{*}{59} & \multirow{2}{*}{$<0.001^{*}$} \\
\hline After & $2.83(1.13)$ & & & & \\
\hline \multicolumn{6}{|c|}{ Control group } \\
\hline After & $2.33(0.94)$ & \multirow{2}{*}{-0.04} & \multirow{2}{*}{-0.629} & \multirow{2}{*}{59} & \multirow{2}{*}{0.532} \\
\hline Before & $2.37(1.01)$ & & & & \\
\hline \multicolumn{6}{|c|}{ BMI $\left(\mathrm{Kg} / \mathrm{m}^{2}\right)$} \\
\hline \multicolumn{6}{|c|}{ Experimental group } \\
\hline Before & $24.70(4.66)$ & \multirow{2}{*}{1.57} & \multirow{2}{*}{3.607} & \multirow{2}{*}{59} & \multirow{2}{*}{$0.001 *$} \\
\hline After & $23.13(4.22)$ & & & & \\
\hline \multicolumn{6}{|c|}{ Control group } \\
\hline After & $24.47(4.73)$ & \multirow{2}{*}{-0.14} & \multirow{2}{*}{-0.558} & \multirow{2}{*}{59} & \multirow{2}{*}{0.579} \\
\hline Before & $24.51(4.85)$ & & & & \\
\hline
\end{tabular}

\footnotetext{
* p-value $<0.01$
} 
Table 3. Comparison of physical activity in the intervention group and the control group before and after intervention (McNemar Test).

\begin{tabular}{|c|c|c|c|c|c|c|}
\hline \multirow{2}{*}{ Physical activity } & \multicolumn{3}{|c|}{ Experimental group (N=60) } & \multicolumn{3}{c|}{ Control group (N=60) } \\
\cline { 2 - 3 } & Before N (\%) & After N (\%) & P-value & Before N(\%) & After N(\%) & P-value \\
\hline Adequate & $15(25.0)$ & $49(81.6)$ & \multirow{2}{*}{$<0.001 * *$} & $18(30.0)$ & $23(38.3)$ & \multirow{2}{*}{0.762} \\
\cline { 2 - 3 } & $45(75.0)$ & $11(18.3)$ & & $42(70.0)$ & $37(61.6)$ & \\
\hline Inadequate & \multicolumn{3}{|l|}{} & & &
\end{tabular}

$*$ p-value $<0.01$

programs enhanced grade 4-6 school students to have learned more about physical activity. As a result, these students have gained knowledge and changed their attitude to do more physical activity, which helps overweight and obese students to burn fat to reduce their BMI [17].

Our study results were also consistent with the study of Sukchaisong et al., which applied the Trans-Theoretical Model to promote physical activity in nursing students [18]. The results showed that exercise behaviors of the intervention group were significantly better than before intervention. In addition, Panichkul and Saranbua have adopted the theory TransTheoretical Model to assess exercise behavior change in the elderly patients with hypertension [19]. The results showed that after the program implemented the experimental group increased change in exercise behaviors. Simlilarly, Puranamaniwiwat et al., employed the concept of Trans-Theoretical Model to study the exercise behavior modification in elderly patients with hypertension. The subjects had significantly higher on average score of exercise and eating behavior [20]. From the previous studies, most researchers have adopted the concepts of TransTheoretical Model to study exercise behavior change in teenager or adult subjects successfully. However, the use of such theories to promote physical activity for upper secondary school students (grade 4-6) was also successful. The students were able to change their physical activity and increase performing physical activity more regularly. It can be explained that the process in the model can motivate school students to change their physical activity to reduce weight especially in overweight and obese students.

\section{Conclusion}

This study concluded that physical activity promotion program for grade 4-6 school students in Pho Prathap Chang District, Phichit Province applied by the Trans theoretical model or Stage of Change Model showed better modification of their knowledge, attitude, physical activity and BMI of students after intervention.

\section{Recommendation}

1. Students, parents, teachers, school administrators and public health officials in Pho Prathap Chang District, Pichit Province can employ physical activity program to promote physical activity for students to practice both at school and at home.

2. The community leaders can use the findings from this study to provide arrangement of places and the environment in the community to facilitate the proper physical activity for children.

3. The researchers should utilize the study results for further study to assess the sustainability of physical activity in the targeted students.

\section{Acknowledgement}

The authors would like to acknowledge with highly grateful to those involved, including parents and students at the elementary school, the teachers, shool administrators, and community health networks in both inside and outside the area of Pho Prathap Chang District, Pichit Province who encouraged and support this research. We also would like to thank the research funding from the Physical Activities Research Center (PARC), the Office of Thai Health Promotion Foundation.

\section{References}

[1]. Wugnrath J. Obesity among pre-school aged children in Thailand. J of Public Health. 2018;48(3):356-70.

[2]. Center for Disease Control and Prevention. Childhood Obesity Facts: Health Effects of Childhood Obesity. August 27, 2015.

[3]. World Health Organization. Global strategy on diet, physical activity and health. Childhood overweight and obesity. Geneva, Switzerland: WHO, 2010.

[4]. Mistry SK, Puthussery S. Risk factors of overweight and obesity in childhood and adolescence in South Asian countries: a systematic review of the evidence. Public Health. 2015 Mar;129(3): 200-9. PMID: 25746156.

[5]. Department of Health, Ministry of Public Health. Report of obesity in school children. 2018.

[6]. Provincial Health Office Phichit. An annual report of nutritional status surveillance among primary school students, 2017.

[7]. Pyper E, Harrington D, Manson H. The impact of different types of parental support behaviours on child physical activity, healthy eating, and screen time: a cross-sectional study. BMC Public Health. 2016: 24; 16(1): 568. PMID: 27554089. doi: 10.1186/s12889-016-3245-0.

[8]. Yu CY, Zhu X. From attitude to action: What shapes attitude toward walking to/from school and how does it influence actual behaviors? Prev Med. 2016 Sep; 90: 72-8. PMID: 27374942. doi: 10.1016/j.ypmed.2016.06.036.

[9]. Pbert L, Druker S, Barton B, Olendzki B, Andersen V, Persuitte G, et al. Use of a FITLINE to Support Families of Overweight and Obese Children in Pediatric Practices. Child Obes. 2016; 12(1):33-43. PMID: 26788762.

[10]. Natale R, Messiah S, Asfour L. Obesity Prevention Program in Childcare Centers: Two-Year Follow-Up. Am J Health Promot. 2017; 31(6): 502-510. PMID: 27630110.

[11]. Physical Activity Research Center, Thailand. A survey of physical activity among primary school students. 2016.

[12]. Cheychom G. Physical activity among primary school students in Krabi Province, Thailand. Journal of Institute of Physical Education. 2015; 7(1): 29-38.

[13]. Prochaska JO, Velicer WF. The trans-theoretical model of health behaviour change. Am J Health Promot. 1997; 2(1): 38-48. PMID: 10170434.

[14]. Yammen P, Duangsong R. The Effects of health promotion program by application of health belief model and social support on behavioral modification for weight control among overweight students at level 5 of primary school, Muang District, Phitsanulok Province. KKU Res J (GS). 2012; 12(1): 57-67.

[15]. Uttarachai A, Banchonhattakit P. Effect of Health Promotion Program in Food Consumption and Exercise Behaviour Modification by the Application of Promotion Motivation Theory and Social Support for Overweight 
Prevention among the Sixth - Grade Students in Khon Kaen Municipality. Srinakarind Medical Journal. 2013; 28(4): 469-76.

[16]. Kaewtes V, Lapvongwatana P, Vatanasomboon P. Effects of dietary and physical activity behaviour promotion program for overweight students in Bangkok metropolitan school. Journal of Public Health. 2013; 43(1): 94-106.

[17]. Saimuang S. Factors correlated with the incidence of obesity among primary school students in Muang District, Kamphaengphet. Naresuan J. 2016;12:706-20

[18]. Sukchaisong N, Pitchayapinyo P, Klumpakorn S. An application of Transtheoretical Model to promote exercise for nursing students at Faculty of
Nursing Kuakarun, Medical Srvice Department, Bangkok. Journal of Public Health Nursing. 2011; 25(1): 1-15.

[19]. Panidchakul K, Samranbua A. An application of Transtheoretical Model to promote exercise. The Journal of Boromarajonani College of Nursing, Nakhonratchasima. 2013; 19(1): 66-76.

[20]. Puranamaneeviwat P, Danyuthasilpe Ch, Noosorn N, Pachanban P. Effects of behaviour change program among essential hypertensive patients. Journal of Nursing and Health Services. 2014; 8(3): 223-33. 